\title{
Review filling the gap of Brachiaria decumbens (signal Grass) research on clinico- pathology and haemato-biochemistry in small ruminants: a review
}

\begin{abstract}
Brachiaria decumbens (signal grass) is a highly productive tropical grass that is widespread in some tropical countries due to its adaptation to a wide range of environments and soil types. However, a limiting factor for the use of this grass is its toxicity from steroidal saponins. Sporadic outbreaks of hepatogenous photosensitization in ruminants grazing on this grass have been reported. Sheep are more susceptible than other animal species and the young are more susceptible than adults. This review article will critically shed light on the B. decumbens profile, its toxic compounds, mechanisms, clinical responses, blood profile alterations, pathological changes, and acute phase responses related to signal grass intoxication. Further research is needed to integrate new findings on $\mathrm{B}$. decumbens intoxication with previous preventive and therapeutic trials to minimize or remove its deleterious toxic effect.
\end{abstract}

Keyword: Brachiaria decumbens; Steroidal saponins; Clinical sign; Blood profile; Pathology; Acute phase proteins 